\title{
Assessing the Relationship of Web-based Cooperative Learning and Adult Students' English Learning in the Perspective of Interactive Hypothesis
}

\author{
Xiaomin Gan \\ Chengdu Radio \& Television University, \\ Sichuan, China 610051
}

\author{
Yuling Ma \\ . School of Foreign Language \\ University of Electronic Science and Technology of \\ China, Sichuan, China 610051
}

\author{
Qinyi Tan* \\ Department of Applied Pedagogy \\ Autonomous University of Barcelona, Spain, 08193 \\ E-mail: tanqinyiedu@hotmail.com \\ *Corresponding author
}

\begin{abstract}
This study analyzed the relevancy between Webbased Cooperative Learning and the outcome of adult students' English learning in the perspective of the Interactive Hypothesis by investigating 692 adult students in the fields of online learning time, online coursework score and posting frequency. It found that the adult students' online learning time, online coursework score and posting frequency all present significant positive relationships with their English learning outcome. Those findings verified that the Web-based Cooperative Learning Model founded on the Interactive Hypothesis can indeed improve students' English ability effectively.
\end{abstract}

Keywords-Web-based Cooperative Learning; English Learning; Adult Education; Interactive Hypothesis

\section{INTRODUCTION}

Foreign Language Acquisition (FLA) refers to the process in which foreign language learners gradually improve their foreign language ability (Wang, 1985). As an independent discipline, FLA originated in the early 1970s. In nearly 40 years, the research of FLA has been in full swing in the whole world. At first, the research of FLA mainly focused on language teaching. Therefore, the theory was put into teaching practice and showed important guidance to foreign language teaching (Jiang, 1999). However, when it comes to language learners' individual difference, there are still some problems about the theory. Hence, the concentration of FLA research turned from the process of teaching to the process of learning. Foreign language acquisition is a very complicated phenomenon. Its multiple research forms are reflected in: some scholars research foreign language learners' speech act; some focus on foreign language learners' psychological process; some pay attention to foreign language learners' competence; some emphasize social factors which influence foreign language acquisition, and so on (Eliss,1994).

\section{LITERATURE REVIEW}

Long's Interactive Hypothesis is a very important theory in foreign language teaching and learning. It holds that types of interaction include comprehensive input, feedback for foreign language forms and meaningful output. Interaction can promote the development of interlanguage because it effectively connects language input, learners' internal motivation with language output (Long, 1996).

While, originally, Input Hypothesis was proposed by Krashen, which insisted that language input is the most principal step during foreign language acquisition. Language ability can be gradually formed only by continuous comprehensive language input instead of being taught. Obtaining comprehensive input as more as possible is the key to acquire a language. If an acquirer is at stage or level $i$, the input he or she understands should contain " $\mathrm{i}+1$ ". In other words, the language which learners are exposed to should be just far enough beyond their current competence that they can understand most of it but still be challenged to make progress (Krashen, 1985).

And Swain put out the Output Hypothesis theory at first. He believes that obtaining comprehensive input isn't the final means to acquire a language. Only depending on comprehensive input, learners cannot reach a proficient language level. Successful language learners need not only a large number of comprehensive language knowledge input, but also meaningful language knowledge output (Swain, 1995).

Hence, it is obvious that Long's Interactive Hypothesis theory is founded on the basis of Krashen's Input Hypothesis theory and Swain's Output Hypothesis theory.

This study presents the results of a study that examines the impact on English learning outcome among Chinese adult students of web-based cooperative programs. The Web-Based Cooperative Learning (WBCL) is such a learning method that is based on web technologies (i.e., 
computer and internet). Moreover, WBCL focuses on the roles of the students, aiming to generate a platform where the students could not only study but also interact/discuss with their classmates and teachers (Markkanen and Ponta, 2001). Hence, WBCL means applying the web technologies in the learning processes of the students (i.e., using the E-Learning), where at the same time generating a platform where the students could frequently cooperate with their classmates and teachers (Mohaiadin, 2000). In other words, the WBCL focuses on the interests of the students (i.e., be studentoriented), aiming to make their learning experiences to be more convenient and effective (Bocchi, 2004; Hiltz \& Shea, 2005; Ismail, 2001; McEwen, 2001). In this way, students could communicate and cooperate with each other, so as to achieve better performances in their learning (Slavin, 1983). Overall, in WBCL, teachers are considered as 'guides' for students, and students should learn by themselves (i.e., conduct active learning) through the internet and attempt to cooperate with their peers to achieve better learning performances in their studies with the help of the web technologies (e.g., posting on the discussion boards, etc.) (Johnson and Johnson, 1986). Hence, the characteristics of the WBCL could be concluded as below (Berge and Dougherty, 2000).

\section{MEthodology}

\section{A. Research purpose}

The principal purpose of this study is to improve the understanding of the relationship between the Web-Based Cooperative Learning Programs and the English learning outcomes of Chinese adult students.

The study will examine the relationships between the levels of the engagements in the Web-Based Cooperative Learning (WBCL) programs (i.e., online learning time, posting frequency and online coursework score) and the English learning outcome (i.e., final English test scores) of the Chinese adult students.

The research question is: 'Are there any correlations between using the Web-Based Cooperative Learning (WBCL) programs and the English learning outcomes (written English test performance) of adult students?' In this research question, the levels of engagements of the students in Web-Based Cooperative Learning (WBCL) programs would be assessed by three variables: online learning time, posting frequency and online course score i.e. group project scores; the final English learning outcomes of the students in English 1 module would be assessed by the final written test scores of this module. Therefore, three kinds of relations would be examined. (1) The relations between online studying time (independent variable) and written English test marks (dependent variable). (2) The relations between posting frequencies (independent variable) and written English test marks (dependent variable). (3) The relations between online coursework marks i.e. group project (independent variable) and written English test marks (dependent variable). Overall, the aim of this research question is to examine whether there are any links between three independent variables and adult students' English learning outcomes. Linear Regression (LR) analysis would be implemented in this research question, and all the independent variables would be entered as predictors of the dependent variable (i.e. mark in the written English test) one by one and then in a same LR.

\section{B. Sample}

The sample is 692 adult students who are learning English as a Foreign Language (EFL) through Web-Based Cooperative Learning (WBCL) in S university. The sample S university is an open university located in Sichuan Province.

The local government pays much attention to English learning and teaching from primary schools to higher education. This university is well equipped with advanced technologies, and accepts adult students with different backgrounds and provides different online courses and can grant degrees for qualified adult students. English 1 module during 2013 (spring semesters) was selected. The assessment is made up of two parts. The first part is the on-line learning program (this consists of 3 parts: online learning time, posting frequency and online coursework i.e. group project, with $10 \%$ of the total marks for each part and the total scores for the continuous assessments would be $30 \%$ ). In this study, online learning time means the hours that the students have spent on their online English learning during their English 1 module studies; posting frequency represents the number of discussion topics the students have posted on the discussion boards during their English studies in Module English 1; online course scores of the students are the group project scores of the students during their online learning; final English test scores are the final closed-book test scores of the students in their English 1 module after the online course learning. The second part is the final written test, with $70 \%$ of the total scores. So the full module score is $100 \%$, with the passing mark of $60 \%$.

\section{Instruments}

Data Collection: Questionnaires were used to get the personal information of gender, age, profession, family background and their views on Web-based Cooperative Learning platform's effectiveness and utilization ratio.

Data Analysis: By using statistical analysis software Minitab 16.0, linear regression was carried out to analyze the data.

\section{RESULTS OF THE SIMPLE LINEAR REGRESSION}

\section{A. The relationship between online learning time (independent variable) and written English test results (dependent variable)}

The first Simple Linear Regression (SLR) is designed to investigate the relationship between online learning time of the students and their written English test results. According to the results (i.e., Table 1), there is a significant positive relationship between the online learning time and written English test results of the students. Specifically, the English test scores of the students will increase 1.95 units (i.e., $1.95 \%$ ) if the online learning time of the students increases 1 unit (i.e., one hour). In addition, according to this regression, 
this positive relationship between the online learning time and the final English test scores of the students is significant at 95 levels since the $p$ value is quite small (i.e., less than 0.05). Also, this positive relationship could be seen in Figure 1. Furthermore, the assumptions of the regression are checked in $\mathrm{C}$. Based on the results, the normality assumptions of the residuals are generally complied with, since the points in the Q-Q plot (top left picture in Figure1.) are generally distributed around the 45 degree lines and the histogram of the residuals (bottom left picture in Figure 1) generally formed a normal curve. Also, the residuals seemed to have constant variances since the points in the top right picture of Figure 1 are randomly distributed around the axis. In addition, the independence assumption of the residuals is generally obeyed, since there are not significant patterns in the bottom right picture of the Figure1. Overall, the assumptions of the regression are not violated in general.

TABLE 1: SLR BETWEEN WRITTEN TEST RESULTS AND ONLINE LEARNING TIME.

Regression Analysis: written_test_results versus onlinz_learning_time

The regession ecuation is

written_test_results $=-28.0+1.95$ onl ne_learning_time

\begin{tabular}{|c|c|c|c|c|}
\hline Pedictior & Coef & SE Coef & T & P \\
\hline Constent & -28.000 & 2.630 & -10.64 & 0.000 \\
\hline on ine_leaming_time & 1.95016 & 0.37019 & 27.78 & 0.000 \\
\hline
\end{tabular}

$S=9.31515 \quad R-S q=52.8 \% \quad R-S q i a d j)=52.3 \%$

\begin{tabular}{|c|c|c|c|c|c|}
\hline \multicolumn{6}{|c|}{ Analysis of Variance } \\
\hline Source & $\mathrm{D}=$ & SS & MS & $\mathrm{F}$ & $P$ \\
\hline Regression & 1 & 66980 & 66980 & $7 \bar{l} 1.91$ & 0.000 \\
\hline Residual Eror & 689 & 59786 & 87 & & \\
\hline Total & 690 & 126766 & & & \\
\hline
\end{tabular}

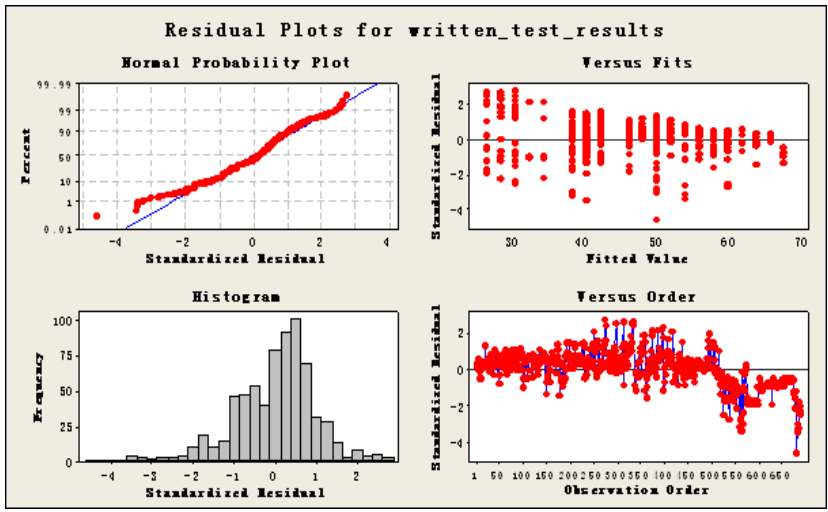

Figure 1 Assumptions of the SLR

Long's Interactive Hypothesis holds that the types of interaction include obtaining comprehensive input. For these 692 non-English major freshmen, the Web-based Cooperative Learning platform of this university is the main approach for acquiring English language knowledge systematically. On this platform, according to their own English ability, they automatically choose comprehensive language knowledge to acquire. By this way, the individualized education mode is realized, which traditional English classes cannot provide. The findings indicate that the more time students spend on online learning, that is, the more comprehensive input acquired from this Web-based
Cooperative Learning platform, the better performance they can obtain in their written English test.

\section{B. The relationship between the online course score (independent variable) and written English test results (dependent variable)}

The second regression is employed to investigate the relationship between the online course (i.e. group project) results and the written test results of the students who have enrolled in the module of English 1. According to the results, there is a significant positive relationship between the online course results and the written test results of student (Table 2). Specifically, the scores of the students would increase 1.68 units $(1.68 \%)$ if the online course results of the students increase 1 unit. Also, this positive relationship between the online course results of the students and their written test scores of English 1 is significant at 95\% levels. This is because, in this regression, the $p$ value of the coefficient of online course results is quite small (i.e., less than 0.05). This positive relationship could also be supported by the picture in Figure 2.

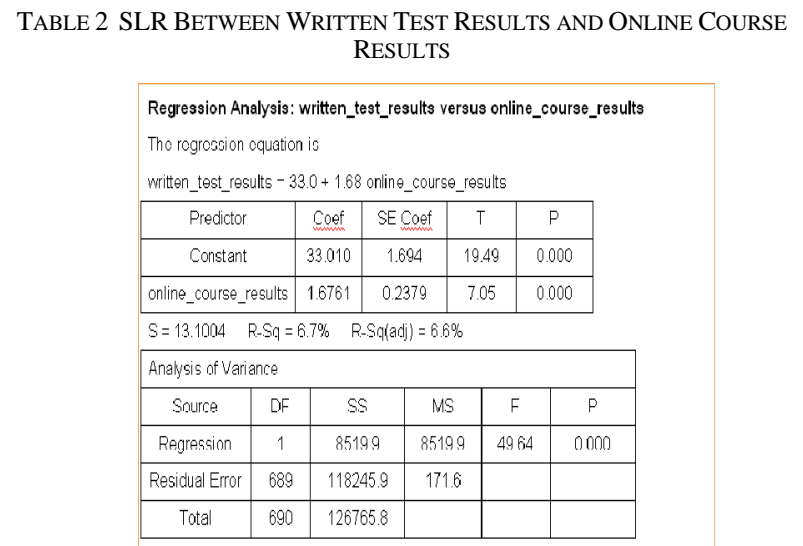

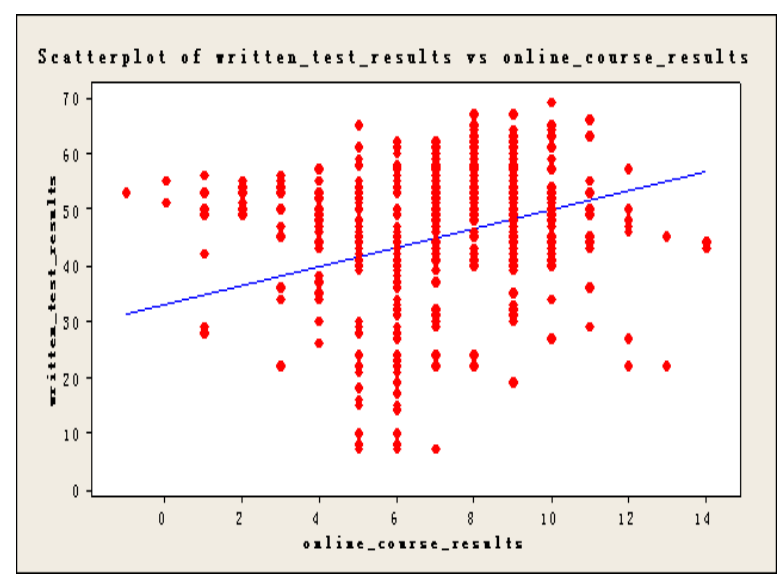

Figure 2: SLR between written test results and online course results

When considering the assumptions of the regression, the normality assumptions of the regression seem to be generally not violated as suggested by the top and bottom left picture in Figure 3 Specifically, in the Q-Q plot, the points are 
generally distributed around the 45 degree line, and - in the histogram - the distribution of the residuals generally follows a curve pattern of the normal distribution. Also, the assumption of the constant variances of the residuals does not seem to be significantly violated since the points in the top right picture of Figure 3 seem to be randomly distributed around the axis. In addition, the independence assumption of the residuals does not appear to be violated since it appears that the points in the bottom-right picture in Figure 3 do not follow some patterns of positive or negative autocorrelations.

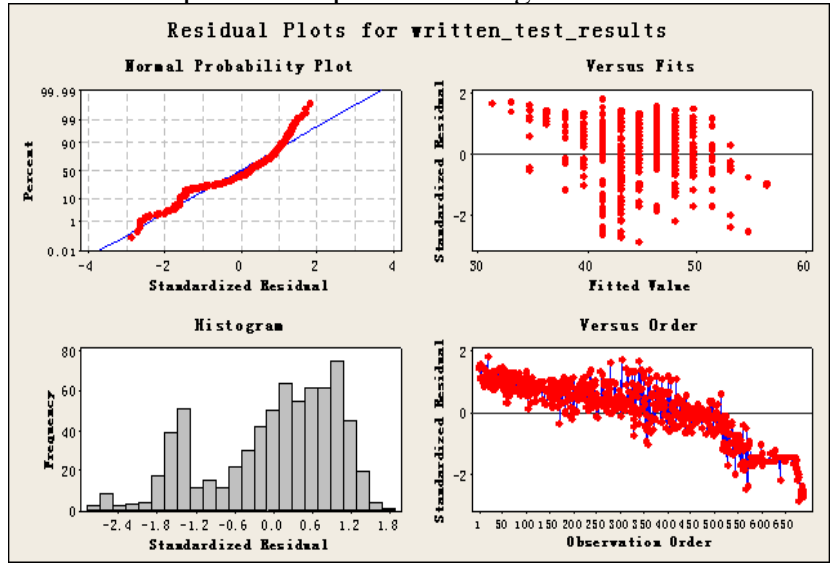

Figure 3 Assumptions of the SLR

Long's Interactive Hypothesis insists that besides comprehensive input, the types of interaction also include meaningful output. Only obtaining comprehensive input is far from mastering a foreign language. Learners must continuously consolidate acquired language knowledge by meaningful language output. Through the Web-based Cooperative Learning platform, teachers group the students and assign English learning tasks to every group. On this platform, group members exchange ideas, divide the work and cooperate with each other. The better the group task is completed, the higher the score is. By encouraging students to positively participate in online cooperative tasks and put what they have acquired into practice use, this platform offers students a great language output approach. The findings indicate that the higher the online course score is, that is the higher the students' participation degree is and the better they perform in online course, the higher their written English test score is. Long's Interactive Hypothesis provides solid theoretical support for the founding of this Web-based Cooperative Learning platform.

C. The relationship between posting frequency (independent variable) and written English test results (dependable variable)

The third Simple Linear Regression (SLR) is designed to examine the relationship between the posting frequency and the written test results. According to the results, there is a positive relationship between the posting frequency and the written test results (Table 3 ). In details, the scores of the students in the module of English 1 will increase 2.8 units (i.e., 2.8\%) if the posting frequency increases 1 unit (i.e., one additional posting). In addition, this positive relationship between the posting frequency and the written test results is significant at $95 \%$ levels since the $p$ value is quite small (i.e., less than 0.05). This relationship could also be seen in Table 3.

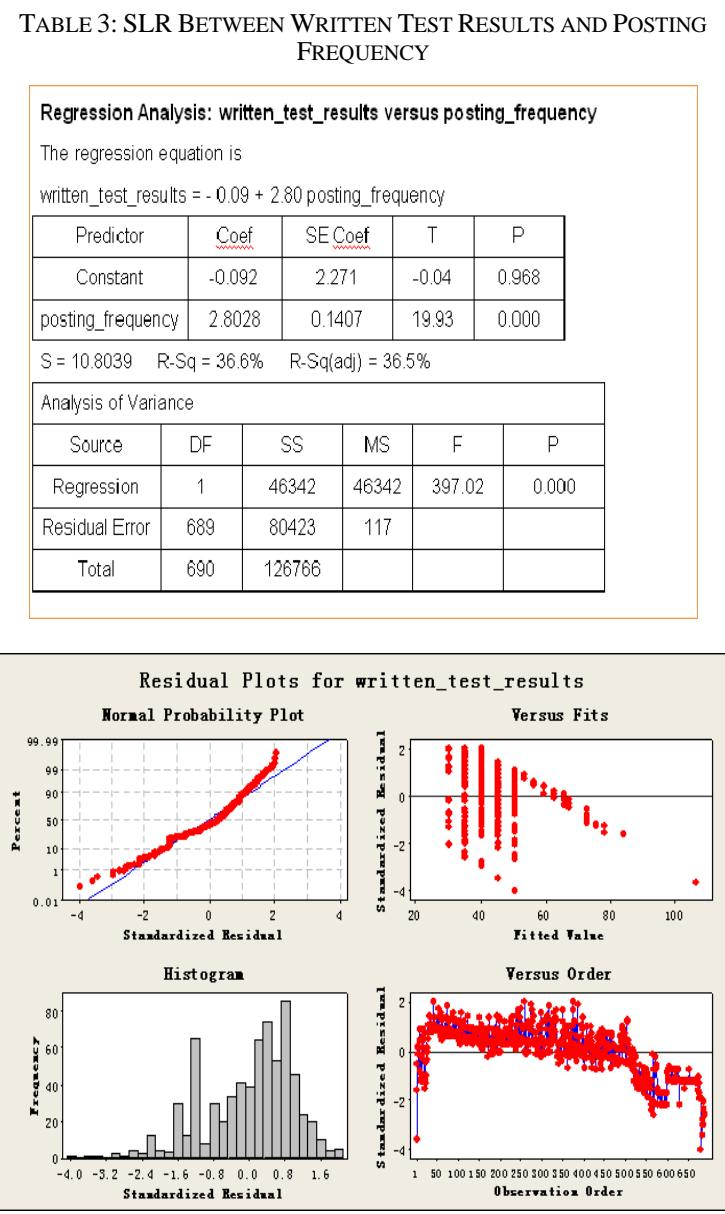

Figure 4: SLR between written test results and posting frequency

In terms of the assumptions of the regression, the pictures in the top and bottom left of Figure 4. showed that the normality assumption of the regression is generally not violated. In addition, the independence assumption of the residuals are generally not violated, because there are no positive or negative autocorrelation patterns being observed in Figure4. However, the assumptions of the constant variances of the residuals have been slight violated, since the top right picture in Figure 4. indicates that the points are not distributed randomly around the axis.

Long's Interactive Hypothesis also believes that feedback on foreign language forms is very important for foreign language learning. By posting messages on the Web-based Cooperative Learning platform, students raise problems and puzzles they meet during the process of foreign language learning, or describe what they have seen and heard in English. After posting messages, students will receive feedback from their classmates or teachers, including answers or solutions to their questions or 
problems, pointing out the grammar, sentence, and vocabulary spelling mistakes and so on. Undoubtedly, the feedback can help students find out their deficiency in English learning and correct it in time. The findings indicate that the higher students' posting frequency is, the higher their English written score is. Therefore, the Web-based Cooperative Learning platform founded in the perspective of Interactive Hypothesis provides adult students with a useful way to learn English.

\section{CONCLUSION}

There is a significant positive relationship between the online learning time and written English test results of the students. Therefore, the more time students spend on online learning, that is, the more comprehensive input acquired from this Web-based Cooperative Learning platform, the better performance they can obtain in their written English test.

There is a significant positive relationship between the online course score and written English test results of the students. Actually, online group learning is different from the traditional classroom team learning in China, which could stimulate students' motivation. Obviously, it is convenient for adult students to communicate with their peers and teachers since there is no any restriction for time and location. In particular, there is no any worries for adult students to lose fame in front of others, that is to say online group learning could build their confidence and cultivate their autonomy in English learning to some extent. Also, during the learning processes of the project, the grammars that are required in this module have been effectively practiced, and the students who have mastered these grammars better are more likely to get higher marks in their final tests. Clearly, online course or group project has positive influences on final English performance for adult students. Therefore, the Web-based Cooperative Learning platform founded from the aspect of Interactive Hypothesis provides English learning students with effective language output approaches, helps students build self-confidence and nurtures them the ability of consciously putting the acquired language knowledge into practice use.

There is a significant positive relationship between the posting frequency and written English test results of the students. After posting messages on the Web-based Cooperative Learning platform, students can receive feedback from their classmates or teachers, which can help them timely solve the problems existing in the process of acquiring knowledge of English. Therefore, the Web-based Cooperative Learning platform founded from the aspect of Interactive Hypothesis offers students an excellent way to rethink the foreign language forms and tackle the problems they have met, which is undoubtedly beneficial to students' acquiring English language knowledge correctly.

To sum up, the Web-based Cooperative Learning platform founded from the aspect of Interactive Hypothesis indeed provides adult students with many benefits. Through autonomous online learning, students obtain comprehensive input; during the process of participating online cooperation projects, they integrate their foreign language knowledge and output it; after posting messages, according to classmates' and teachers' feedback, they timely settle their problems existing in the process of English learning. The Web-based Cooperative Learning platform effectively connect the input and output of English language knowledge and students' internal motivation, providing high-efficiency study environment for English learners. In this environment, students are the subject of English learning, while teachers just play the role of a guide. The teaching model is quite different from the traditional one. With the continuous development of network technology, Web-based Cooperative Learning will increasingly show its superiority.

\section{REFERENCES}

[1] Berge, Z., and Collins, M. Design Guidelines for Web-Based Courses. In B. Abbey (Ed.), Instructions and Cognitive Impacts of Web-Based Education. PA, USA: Idea Group Publishing, 2000, pp. 32-40.

[2] Bocchi, J., Eastman, J.K., \& Swift, C.O.. Retaining the online learner: profile of students in an online MBA program and implications for teaching them. Journal of Education for Business, 3, 2004, pp.245253.

[3] Ellis, R.. The Study of Second Language Acquisition, Oxford: Oxford University Press, 1994.

[4] Hiltz, S.R \& Shea, P.. The student in the online classroom. In S.R. Hiltz \& R Goldman (Eds.) Learning Together Online: Research on Asynchronous Learning Networks, Mahwah, NJ: Lawrence Erlbaum Associates. pp. 145-168, 2005.

[5] Ismail, Z.. Learning for the Knowledge Society: National E-Learning Agenda (NELA). Malaysian International Conference \& Exhibition on Electronic Learning 2001, Petaling Jaya, Malaysia, June 2001.

[6] Johnson D. W., \& Johnson R. T. Learning together \& alone: Cooperation, competition and individualization (2nd Ed.). NJ: Prentice-Hall: Englewood Cliffs, 1986.

[7] Krashen, S. The Input Hypothesis: Issues and Implications. New York: Longnaan Group Limited, 1985.

[8] Long, M. The role of the linguistic environment in second language acquisition. In W. Ritchie \& T. Bhatia (Eds.), Handbook of Second Language Acquisition. New York: Academic Press, 1966, pp.451-452.

[9] Markkanen, H., \& Ponta, D.. Web Tools for Collaborative Project Learning. In Montgomerie, C. \& Viteli, J. (Eds.), Proceedings of EdMedia 2001: World Conference on Educational Multimedia and Hypermedia, Norfolk, USA: AACE, 2001, pp.1236-1238.

[10] McEwen, B.C.. Web-assisted and online learning. Business Communication Quarterly, vol.64, 2, 2001, pp.98-103.

[11] Mohaiadin, J. D. (2000). Information Technology/MSC: Who benefits most? International Conference on Education \& ICT in the New Millennium in Kuala Lumpur, Malaysia, October 2000,

[12] Slavin, R. E. Cooperative learning. New York: Longman, 1983.

[13] Swain, M.. Three functions of output in second language learning. In G. Cook \& B. Seidlhofer(eds.). Principle and Practice in Applied Linguistics. Oxford: Oxford University Press, 1995.

[14] Jiang, Zukang. A Research on Foreign Language Acquisition. Beijing: Foreign Language Teaching and Research Press, 1999.

[15] Wang, Zongyan. Explorations of Linguistic Issues. Shanghai: Shanghai Foreign Language Education Press, 1985. 